Volume 11, Issue 12, December 2020, pp.1642-1651, Article ID: IJM_11_12_150

Available online at http://iaeme.com/Home/issue/IJM?Volume $=11 \&$ Issue $=12$

ISSN Print: 0976-6502 and ISSN Online: 0976-6510

DOI: 10.34218/IJM.11.12.2020.150

\title{
THE EFFECT OF TIME MANAGEMENT ON SUBJECTIVE WELL-BEING AMONG UNIVERSITY STUDENTS
}

\author{
Dr. C.S. Yadav \\ Professor, Graphic Era Hill University, Uttrakhand, India. \\ Shivani Monga \\ Assistant Professor, Graphic Era Hill University, Uttrakhand, India. \\ Dr. Sunita Tanwar \\ Assistant Professor, Central University Haryana, Mahendergarh, India..
}

\begin{abstract}
In a study of subjective well-being targeting university students, Claessens, et al., (2007) said that spending four years of a fulfilling university is the most important thing for university students, who are preparing for the future. According to Denovan, A., \& Macaskill, A. (2017), it is necessary for students to feel happiness in order for the College to function and engage in learning (Diener, E., at al., 2009). They tend to solve problems efficiently and seek goals and success. In addition, Bücker, (2018) stated that in order to more positively capture mental health in adolescence, it is necessary to pay attention to life and positive feelings toward oneself. The subjective feeling of well-being is cited as a positive emotion. From these previous studies, it seems that the factor of feeling of well-being plays an important role for university students to enhance their student life.
\end{abstract}

Key words: Time Management, Subjective Well-Being, Self-Efficacy, College Students.

Cite this Article: C.S. Yadav, Shivani Monga and Sunita Tanwar, The Effect of Time Management on Subjective Well-Being Among University Students, International Journal of Management, 11(12), 2020, pp. 1642-1651.

http://iaeme.com/Home/issue/IJM?Volume=11\&Issue=12 


\section{INTRODUCTION}

While it is said that the happiness of university students is important, since the 1960s, there are students who leave the College for a repeat year or leave the College due to apathy or a decrease in motivation to study (Roth, ET AL., 2017). In addition, it has been pointed out that poor mental health of students causes College refusal, which eventually leads to repeated years and leave of absence (Samdal, O. (2001). Reasons for dropout and leave of absence include financial reasons, illness, injury, poor academic performance, and maladjustment in College life. From these reports, it seems that not only physical health of university students but also mental health deterioration is related to College refusal, leave of absence, and withdrawal from College.

One of the factors related to the deterioration of mental health is one of them is that he is busy in life. In addition, many university students seem to be busy because they spend most of their time studying and spending part-time jobs and club activities in the meantime. In order to accomplish a variety of tasks and work such as College work and part-time work in a limited time of 24 hours and achieve high quality results, in addition to simply having knowledge and skills, time management ability is required (Suldo, S. M, et al., 2015). Time management is a way to use time efficiently and is one of the essential strategies for modern working people and students. Regarding the definition of time management, many focus on actions such as "technology", "method", "practice", and "procedure", and behavior that effectively uses time to achieve it". Therefore, in this research as well, time management is regarded as "action". Time management is associated with work and academic performance (Ai-bing, F. U. (2010), tress reaction (Osmond, T. W., 1994).), tension (Macan, et al., 1990), emotional fatigue (Peeters \&Rutte, 2005), insecurity (Kelly, 2003), work load (Hafner \& Stock, 2010).

Furthermore, FAN, C. Y. (2012) cite time management as a method to deal with stress due to the busy life, which is thought to be the cause of university students not going to College. In this way, research on time management is actively conducted overseas, and it can be seen that it has a positive effect on various aspects such as mental health as well as work and academics. Therefore, it is considered that time management helps to lead an adaptive life. However, there are still few studies on time management in India. Zhang, Y., \& Chen, M. (2018) among university students, those who do not have a lot of work but tend to have a deadline, and those who do not get much results even if they adhere to the deadline in order to do it quickly,losing social credibility, being prone to low evaluation, and acquiring time management ability are one of the important issues for university students, and it is important to conduct research on time management in India as well. It points out that. In addition, time management reduces psychological stress by increasing the sense of control over time. Even in India, time management is a method of efficiently performing tasks and tasks. In addition, it suggests that it may contribute to the promotion of mental health by reducing stress. In recent years, research focusing on the positive aspects of human psychology has been attracting attention, and has only examined negative indicators of mental health. However, since it is necessary to consider including positive indicators in the future and to improve the usefulness of time management, we will examine the effect of time management on positive mental health. Seems to be significant. It is thought that clarifying this relationship will help university students to lead a fulfilling student life. In addition, it is considered that self-efficacy mediates the relationship between time management and mental health. Self-efficacy is one of the core concepts of social learning theory or social cognitive theory (Bandura, 1977), and it recognizes the possibility that an individual can effectively perform necessary actions in a certain situation. It is said that how much one has self-efficacy for a certain problem or task predicts changes in individual behavior and changes inappropriate emotional reactions and behaviors. One is to influence behaviors in 
a way that is specific to the tasks and scenes that are often used in clinical and educational research.

Generalized Self-Efficacy (GSE) is a self-efficacy that affects behaviors in more generalized everyday situations in the longer term, without depending on specific individual tasks or situations. There is an individual difference in the tendency to perceive GSE higher or lower, and this high or low may affect overall behavior of the individual. Judge, T. A., \& Bono, J. E. (2001) point out that GSEs are formed from past experiences of success and failure and have individual differences, while at the same time not only in specific situations but also in unexperienced ones. Suggests that it will influence the expectation of adaptive treatment in new situations (Betz, N. E., \& Klein, K. L., 1996).

Terry, K. P. S. (2002) examined the relationship between university students' time management ability and GSE by using the concrete situation of creating a report task imposed in a class. As a result, it was shown that time management ability is likely to have a high GSE, suggesting that time management ability is more likely to lead to success in a task and successful experience enhances GSE. As a result, the "starting work type with a margin" is relatively high in GSE, and the work is not slow, but it is less than the planned time. The "planned collapse type," which spends much less time writing reports, was shown to have a relatively low GSE. Based on these results, students with a planned or time course that can spend almost the same amount of time as they planned will have a higher GSE, and have the prospect that they will be able to achieve high results. It suggests increasing GSE.

In the validation study, the GSE scale scores were compared between the pathological group with depression or manic-depressive and depressive states, the standard group consisting of healthy subjects, and the high self-efficacy group. As a result, the GSE scale scores of the pathology group were significantly lower than those of the standard group and the high selfefficacy group. In addition, a positive correlation was found between the subjective feeling of health, which subjectively evaluates mental and physical health, and GSE (Narita et al., 1995). These previous studies suggest that GSE is related to both time management and mental health, and therefore is expected to be a mediator between time management and mental health. Therefore, the purpose of this study is to examine the effect of time management on subjective well-being through GSE.

\section{METHOD}

\subsection{Survey collaborator}

The subjects of the survey were 186 students (69 men, 117 women) at University A in the first to fourth years. In addition, 180 complete respondents (67 males, 113 females) were included in the analysis (average age 19.23, $\mathrm{SD}=2.34$ ).

\subsection{Investigation period}

It was held in November 2019-January 2020.

\subsection{Survey method}

It was conducted in a group survey format before or after the lecture. We conducted a self-filled questionnaire survey, in which case we asked for answers anonymously. At the time of requesting a reply, I explained it in writing and verbally, and asked for consent to the reply. The implementation time was about 10 minutes. 


\section{QUESTIONNAIRE COMPOSITION}

\subsection{Fact sheet}

I asked them to fill in the faculty to which they belonged, their grade, age, and gender.

\subsection{Time management scale}

Misra, R., \& McKean, M. (2000) Behavior that uses time effectively to achieve the goal is to measure the "time estimate ( 8 items)". It consists of 19 items of three subscales, "use of time (6 items)" and "living for the day (5 items)". To what extent they apply to themselves, we asked for answers in four cases: "not applicable at all", "somewhat not applicable", "somewhat applicable", and "very applicable".

\subsection{Characteristic Self-Efficacy (GSE) Scale}

It measures self-efficacy that affects behavior in more generalized everyday situations over a longer period without depending on specific individual tasks or situations (Romppel, M., et al., 2013). It consists of 23 items. To what extent they apply to themselves, we asked for answers in five cases: "Not applicable at all", "Not applicable to some extent", "Not applicable", "Applicable to a little", and "Exactly applicable".

\subsection{Subjective well-being scale}

It measures individual differences in psychological health that reflect both cognitive and emotional aspects (Diener, E., 2009), and is "a positive attitude toward life (3 items)", "confidence (3 items)", and "sense of achievement".(3 items)", "No disappointment with life (3 items)" consists of 12 subscales. I asked for answers based on the four-point method according to the question items such as "very happy", "somewhat happy", "not very happy", and "not totally happy".

\section{BASIC STATISTICS}

Table 1 shows the average and standard deviation for each subscale of the time management scale, GSE scale, and subjective well-being scale. 2. Regarding the relationship between time management, GSE, and subjective well-being, Table 2 shows the correlation coefficient for each sub-scale of the time management scale, GSE scale, and subjective well-being scale. Time estimation and time utilization showed a moderate positive correlation with GSE (time estimation: $\mathrm{r}=.53, \mathrm{p}<.01$; time utilization: $\mathrm{r}=.51, \mathrm{p}<.01$ ). Moreover, daily living and GSE had a weak positive correlation $(\mathrm{r}=.35, \mathrm{p}<.01)$. In the estimation of time, positive feeling for life $(\mathrm{r}=.22, \mathrm{p}<.01)$, self-confidence $(\mathrm{r}=.32, \mathrm{p}<.01)$, sense of accomplishment $(\mathrm{r}=.24, \mathrm{p}<.01)$, life No disappointment with $(\mathrm{r}=.21$,A weak positive correlation was shown with $\mathrm{p}<.01)$. In utilizing time, positive feelings for life $(\mathrm{r}=.32, \mathrm{p}<.01)$, sense of accomplishment $(\mathrm{r}=.38, \mathrm{p}<.01)$, disappointment for lifeThere was a weak positive correlation with insensitivity $(\mathrm{r}=.24, \mathrm{p}<0.01)$. In addition, confidence showed a moderately positive correlation $(\mathrm{r}=.42, \mathrm{p}<0.01)$. In his daily life, he had confidence $(\mathrm{r}=.24, \mathrm{p}<.01)$, sense of accomplishment $(\mathrm{r}=.20, \mathrm{p}<.01)$, and lack of disappointment with life $(\mathrm{r}=.14, \mathrm{p}<.10)$. It showed a weak positive correlation. However, it did not correlate only with positive feelings about life $(\mathrm{r}=.05$, n.s.).

GSE is a positive attitude toward life $(\mathrm{r}=.41, \mathrm{p}<.01)$, self-confidence $(\mathrm{r}=.66, \mathrm{p}<.01)$, sense of achievement $(\mathrm{r}=.53, \mathrm{p}<.01)$, There was a moderate positive correlation with the lack of disappointment in life $(\mathrm{r}=.54, \mathrm{p}<.01)$. 
The Effect of Time Management on Subjective Well-Being Among University Students

Table 1.Mean and standard deviation for time management, self-efficacy (GSE), and subjective wellbeing

\begin{tabular}{|l|l|l|l|}
\hline \multicolumn{1}{|c|}{ Scale } & \multicolumn{1}{|c|}{ Score range } & \multicolumn{1}{c|}{ Average } & \multicolumn{1}{c|}{ standard deviation } \\
\hline Time management & & & \\
\hline Time estimate & $(8 \sim 32)$ & 19.3 & 4.5 \\
\hline Utilization of time & $(6 \sim 24)$ & 15.1 & 3.9 \\
\hline Living that day & $(5 \sim 20)$ & 10.5 & 3 \\
\hline Self-efficacy (GSE) & $(23 \sim 115)$ & 63.5 & 13.1 \\
\hline Subjective well-being & & & \\
\hline Positive feelings for life & $(3 \sim 12)$ & 8.9 & 1.7 \\
\hline Confidence & $(3 \sim 12)$ & 7.6 & 1.8 \\
\hline Sense of accomplishment & $(3 \sim 12)$ & 7.9 & 1.7 \\
\hline No disappointment for life & $(3 \sim 12)$ & 7 & 2 \\
\hline
\end{tabular}

Table 2. Correlation matrix for time management, self-efficacy (GSE), and subjective well-being Time management

\begin{tabular}{|l|l|l|l|l|}
\hline & \multicolumn{2}{l|}{ Time management } & \\
\hline & Time estimate & Utilization of time & Living that day & Self-efficacy \\
\hline Self-efficacy (GSE) & $.53^{* *}$ & $.51^{* *}$ & $.35^{* *}$ & \\
\hline Positive feelings for life & $.22^{* *}$ & $.32^{* *}$ & 0.05 & $.41^{* *}$ \\
\hline Subjective confidence & $.32 * *$ & $.42^{* *}$ & $.24 * *$ & $.66^{* *}$ \\
\hline Happiness sense of achievement & $.24 * *$ & $.38^{* *}$ & $.20^{* *}$ & $.53^{* *}$ \\
\hline No disappointment for life & $.21^{* *}$ & $.24 * *$ & $.14^{+}$ & $.54^{* *}$ \\
\hline
\end{tabular}

Causal relationship between time management, GSE, and subjective well-being. Next, according to the method of Baron \& Kenny (1986), a mediation analysis is performed with time management as the explanatory variable, subjective well-being as the objective variable, and GSE as the parameter. (Figure. 1).

Table 3 shows the direct effect of time management on subjective well-being and the indirect effect of time management on subjective well-being through GSE. Path diagrams for each subscale are shown in Figure 2.

From Figure. 2, from the results of simple regression analysis and time estimation.A significant positive effect on GSE was seen $(\beta=.53, p<0.001)$.

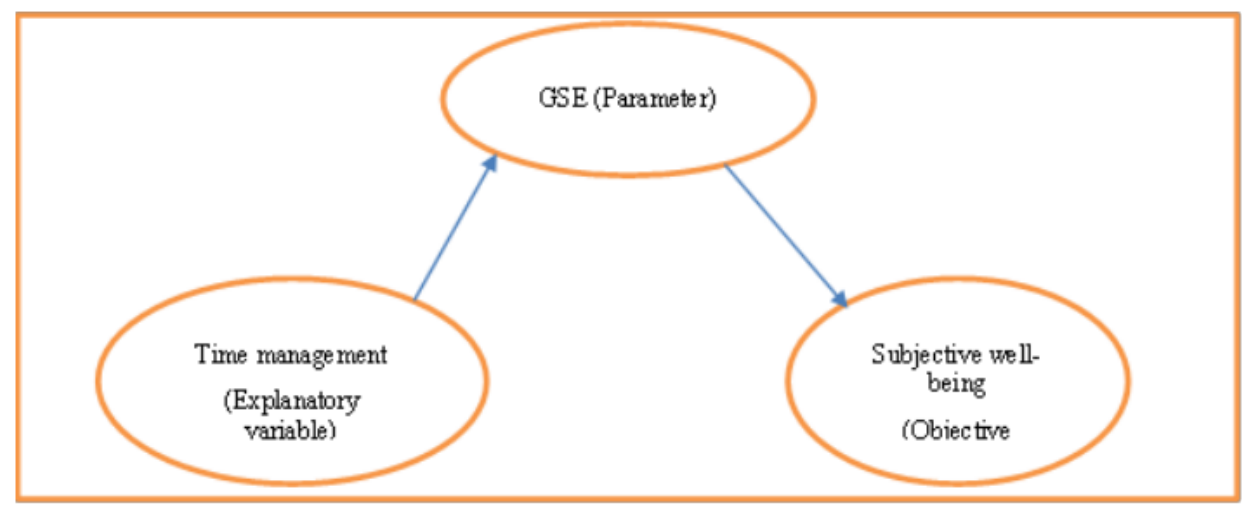

Figure 1. Mediation model of effects from time management by GSE to subjective well-being 


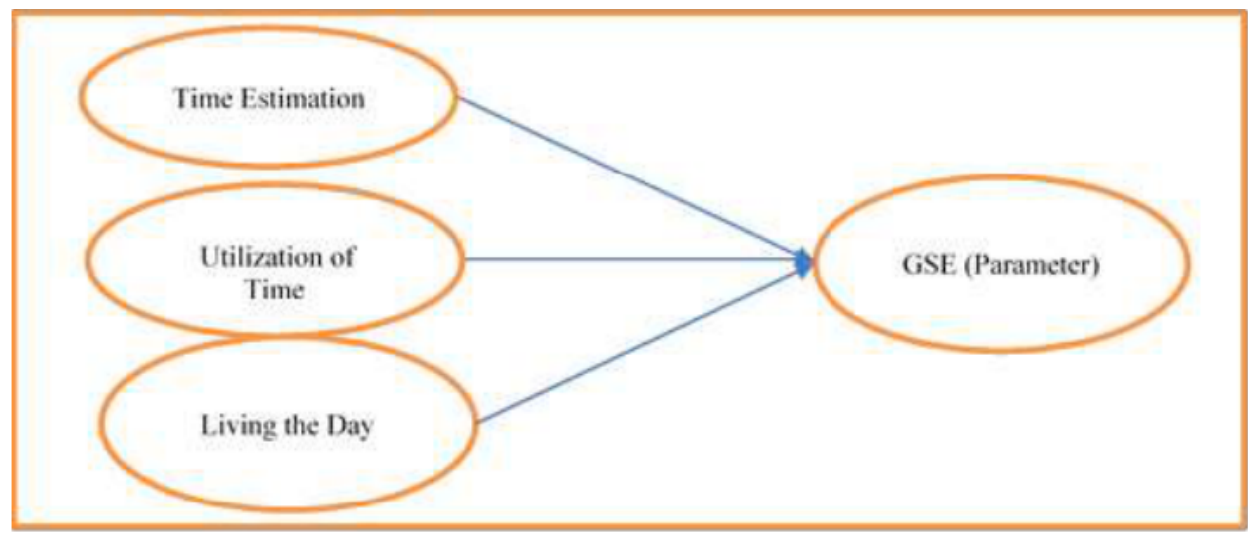

Figure 2. Simple regression between time management dimensions and GSE

Furthermore, when multiple regression analysis was performed using GSE and time estimates as independent variables and the subscale of subjective well-being as a dependent variable, GSE showed positive feelings toward life $(\beta=.40, p<.01)$, Confidence $(\beta=.68, p<.01)$, sense of accomplishment $(\beta=.56, p<.01)$, lack of disappointment with life.

A significant positive effect on $(\beta=.60, p<0.01)$ was seen. Also, from the estimation of time, positive feelings toward life $(B=.23, p<.01)$, confidence $(\beta=.32, p<.01)$, sense of accomplishment $(\beta=.25, \mathrm{p}<.01)$, lack of disappointment with life $(\beta=.21$,A significant positive effect on $\mathrm{p}<.01$ ) was seen.

The bootstrap test (Efron, 1979) was performed to test the indirect effect of time estimation on the subscale of subjective well-being through the GSE. As a result, there was no positive feeling for life $(\mathrm{z}=4.12, \mathrm{p}<.01)$, self-confidence $(\mathrm{z}=5.82, \mathrm{p}<.01)$, sense of accomplishment $(\mathrm{z}=5.12, \mathrm{p}<.01)$, no sense of disappointment for life. $(\mathrm{Z}=5.68, \mathrm{p}<.01)$, and the indirect effect was significant.

From Figure.2, as a result of simple regression analysis, a significant positive effect on GSE from the utilization of time was observed $(\beta=.51, \mathrm{p}<0.01)$. Furthermore, using GSE and time as independent variables, subjective well-being.

Table 3. Direct and indirect effects of the effect of time management on subjective well-being through GSE

\begin{tabular}{|c|c|c|c|c|c|c|c|c|}
\hline \multirow[b]{2}{*}{$\begin{array}{l}\text { Explanatory } \\
\text { variable }\end{array}$} & \multicolumn{2}{|c|}{$\begin{array}{c}\text { Positive feelings about } \\
\text { life }\end{array}$} & \multicolumn{2}{|c|}{ Confidence } & \multicolumn{2}{|c|}{$\begin{array}{c}\text { Sense of } \\
\text { accomplishment }\end{array}$} & \multicolumn{2}{|c|}{$\begin{array}{c}\text { No } \\
\text { disappointment } \\
\text { for life } \\
\end{array}$} \\
\hline & $\begin{array}{l}\text { Direct } \\
\text { Effect }\end{array}$ & $\begin{array}{l}\text { Indirect } \\
\text { Effect }\end{array}$ & $\begin{array}{l}\text { Direct } \\
\text { Effect }\end{array}$ & $\begin{array}{c}\text { Indirect } \\
\text { Effect }\end{array}$ & $\begin{array}{l}\text { Direct } \\
\text { Effect }\end{array}$ & $\begin{array}{c}\text { Indirect } \\
\text { Effect }\end{array}$ & $\begin{array}{l}\text { Direct } \\
\text { Effect }\end{array}$ & $\begin{array}{c}\text { Indire } \\
\text { ct } \\
\text { Effect }\end{array}$ \\
\hline Time estimate & $.02(.23 * *)$ & $.22 * *$ & $\begin{array}{l}-.04 \\
(.32 * *) \\
\end{array}$ & $36^{* *}$ & $\begin{array}{l}.05 \\
(.25 * *) \\
\end{array}$ & $30 * *$ & $\begin{array}{l}-.11 \\
(.21 * *)\end{array}$ & $.32 * *$ \\
\hline $\begin{array}{l}\text { Time management } \\
\text { Utilization of time }\end{array}$ & $.15(.32 * *)$ & $.17 * *$ & $\begin{array}{l}.12 \\
(.43 * *)\end{array}$ & $.31 * *$ & $\begin{array}{l}.14 \\
(.38 * *)\end{array}$ & $24 * *$ & $\begin{array}{l}-.05 \\
(.24 * *)\end{array}$ & $.29 * *$ \\
\hline Living that day & $-.11 \quad(.05)$ & 0.15 & \begin{tabular}{|l|}
02 \\
$(.25 * *)$ \\
\end{tabular} & $.23 * *$ & $\begin{array}{l}.01 \\
(.19 * *)\end{array}$ & $.18^{*}$ & $-.06(.13)$ & $.20 * *$ \\
\hline
\end{tabular}

When multiple regression analysis was performed using the subscale of feeling as a dependent variable, GSE showed positive feeling toward life $(\beta=.33, p<.01)$, confidence $(\beta=.60$, $\mathrm{p}<.01)$, achievement There was a significant positive effect on feeling $(\beta=.46, \mathrm{p}<.01)$ and lack 
of disappointment with life $(\beta=.57, \mathrm{p}<.01)$. Also, from the use of time, positive feelings toward life $(\beta=.32, p<.01)$, self-confidence $(\beta=.43, p<.01)$, sense of accomplishment $(\beta=.38, p<.01)$, There was a significant positive effect on the lack of disappointment in life $(\beta=.24, p<.01)$. The bootstrap test (Efron, 1979) was performed to test the indirect effect of time utilization on the subscale of subjective well-being through the GSE. As a result, positive feelings toward life $(\mathrm{z}=3.65, \mathrm{p}<.01)$, self-confidence $(\mathrm{z}=5.43, \mathrm{p}<.01)$, sense of accomplishment $(\mathrm{z}=4.36, \mathrm{p}<.01)$, lack of disappointment with life $(Z=5.92, p<.01)$, and the indirect effect was significant. From Fig. 2, as a result of simple regression analysis, a significant positive effect from daily living on GSE was observed $(\beta=0.34, p<0.01)$. Furthermore, when multiple regression analysis was performed using GSE and its daily living as independent variables and the subscale of subjective well-being as a dependent variable, GSE revealed confidence $(\beta=.65, p<.01)$ and sense of achievement $(\beta) .=.53, \mathrm{p}<.01$ ), and a significant positive effect on the lack of disappointment in life $(\beta=.57, p<.01)$. In addition, a significant positive effect was seen from daily living on self-confidence $(\beta=.25, \mathrm{p}<.01)$ and sense of accomplishment $(\beta=.19, \mathrm{p}<.01)$. However, there was no significant effect on positive feelings for life $(\beta=.05$, n.s. $)$ and lack of disappointment for life ( $\beta=.13$, n.s.). The bootstrap test (Efron, 1979) was performed to test the indirect effect of daily living on the subscale of subjective well-being through GSE. As a result, self-confidence $(\mathrm{z}=2.66, \mathrm{p}<.01)$, sense of accomplishment $(\mathrm{z}=2.50, \mathrm{p}<.01)$, lack of disappointment with life $(\mathrm{z}=2.76, \mathrm{p}<.01)$, and indirect effects are significant. Met. We examined the mediating effect of GSE on the relationship between time management and subjective well-being. First, as a result of simple regression analysis, it was shown that each time management subscale had a positive effect on GSE. As a result of multiple regression analysis based on the criteria of Hayes, A. F. (2009), GSE, which is a parameter, has a significant positive effect on each subscale of subjective well-being, which is an outcome variable. Was shown. The results of the bootstrap test showed the significance of the indirect effect that time estimation and time utilization influence each subscale of subjective well-being through GSE. In addition, the significance of the indirect effect was also shown in part in daily living. From the above results, it can be said that the hypothesized mediation model (Fig. 1) was supported. In the relationship between time management and GSE, time estimation and utilization of time have a positive effect on GSE. The results support the report that it will be easier to do. In addition, high time management ability can easily lead to success in tasks, and successful experience can improve GSE, and those who manage time can achieve great results in work and education. It is thought that GSE will be increased by producing high results by planning and prioritizing to carry out a certain task. However, even if you can set up a plan, if you spend less time on the task than on the plan and the performance is not good, the GSE will be low, so it is important to make a plan, It becomes more important to actually carry out the tasks as planned.

\section{DISCUSSION}

Regarding the relationship between time management and subjective well-being through GSE, the result is that estimation of time and utilization of time have a positive effect on the subscale of subjective well-being through GSE. From this, it seems that it is possible to have the prospect that adaptive processing will be possible in any situation by performing the tasks as planned and producing high results. As a result, new things can produce high results, and their successful experience is thought to have led to a sense of well-being, such as self-confidence and a sense of achievement. The daily living had a positive impact on the GSE.

Most of the assignments can be submitted in time even if the start and execution of the assignment are postponed in daily life, but even if the degree of achievement (completion) of the assignment is not sufficient as a result, the result can be submitted by myself. Since it does not lead to a penalty for self-evaluation of learning, it is considered that recent university 
students are procrastinating without worrying about achievement of learning/execution (Kim, B., \& Kim, Y. (2017). In other words, I think that if I could submit the credits even if I couldn't perform the tasks in a planned manner and weren't well done, it would have been a successful experience and lead to an increase in GSE. Furthermore, it seems that the increase in GSE also led to an increase in confidence and a sense of accomplishment, which is a subscale of subjective well-being. However, even if they are optimistic about the task, some people may feel regret or self-loathing after procrastinating (Binfet, J. T. (2017), so it is considered that the effect on happiness was not so strong. Also, daily living did not show any positive feelings about life. This is because I don't spend my time in particular because my daily life is "often undecided for the next day" and "I often spend a day on a whim." It is thought that it did not affect the feeling of happiness in the current life.

However, the contradictory result was that GSE increased and happiness increased even if one was living that day without making a plan. This seems to be a student-specific result. For example, university students and working people have different qualities such as "holding responsibility", "appraisal", and "purpose", which is considered to lead to a difference in awareness of time management. If you are a student, you will not be punished if you are late or absent from class. However, as a member of society, you have to take responsibility for your actions. If you are late or absent from the company, it will be considered insane and you will lose credibility. There is a difference in the sense of responsibility between students and members of society because they are greatly involved not only in their own evaluation but also in the evaluation of the company.

In addition, students should be evaluated from the viewpoint of grade evaluation in many cases, it is easy to understand visually, such as the number and performance of reports, and recovery may be achieved by overnight pickling and intuition. However, no matter how high the evaluation of working people is in their work, if the process up to that point is not due to their efforts, or if their attitude toward work does not serve as a model, the evaluation is always high. In other words, university students do not focus on the process of producing results, but on the assignment of tasks.

The emphasis is on achieving results regardless of whether the prosperity is high or low. On the other hand, since the members of society are evaluated not only in the results, but also in the process of producing the results, it is considered that there is a difference in awareness between the students and the members of society regarding the task.

In addition, as for the purpose of tackling tasks and tasks, students are also able to complete tasks from the perspective of how much "help" can be gained by studying, and from the perspective of gaining credit for "self." Many people go. However, since working people work from the perspective of how much they can be useful to the "company" and "society" by working, it seems that there is a difference in the quality of purpose. Moreover, it is considered that differences in the quality, goals, and contents of the tasks that are required by students and working adults lead to differences in awareness of the importance of performing work while managing time. In other words, university students are more conscious of "doing tasks for themselves" than adults, and are evaluated only for themselves, so the process and performance of completing tasks while managing time are emphasized. It seems difficult to put. On the other hand, working people are considered to "work for an organization such as a company." Therefore, it is considered that students who attach importance to the assignment of tasks will be able to complete their assignments even if they live for the day and are able to submit the assignments even if they are close to the deadline. However, in this study, comparing the time management with the daily life of spending a day on a whim, the former had a higher GSE and felt a strong sense of well-being. This shows that time management is important. 
Furthermore, in addition to reducing stress caused by a busy life and psychological stress, time management enhances happiness in this study. It has been shown. Therefore, it was suggested that time management has a positive effect on the positive side of mental health and leads to a fulfilling student life for university students, and it was possible to show the importance of time management.

\section{FUTURE SCOPE}

Currently, poor temporal management skills are postponed. It has been reported that it is a cause of blowout. For this reason, we think that people who do not have the ability to manage time such as planning and prioritizing to carry out certain tasks are procrastinating. In addition, procrastination increases the number of students who cannot complete the task or cannot submit it (Denovan, A., \& Macaskill, A., 2017), and the failure behavior caused by careless mistakes to tackle the task in a hurry. It has been reported that it tends to occur. In addition, because it is a factor that increases depression and anxiety, procrastination is a factor that impairs mental health and interferes with adaptive student life. I think that the. In time management and procrastination, there is a negative correlation between time estimation and utilization of time and procrastination. I think that I can live a student life like this.

Practical research using cognitive behavior therapy can be applied. For people who are not good at time management, those who feel resistance to move while watching the clock "I'm rushed" "I don't want to be tied to time", or a sense of time "about 10 minutes" There are people who are not accurate. By giving such people training that allows them to write down a concrete plan in a schedule book while keeping in mind the time, they can make a reasonable plan and do the plan as planned.

\section{REFERENCES}

[1] Ai-bing, F. U. (2010). A Correlativity Study Concerning Time Management Inclination and Subjective Sense of Well-being among College Students [J]. Journal of Neijiang Normal University, 8.

[2] Betz, N. E., \& Klein, K. L. (1996). Relationships among measures of career self-efficacy, generalized self-efficacy, and global self-esteem. Journal of career Assessment, 4(3), 285-298.

[3] Binfet, J. T. (2017). The effects of group-administered canine therapy on university students' wellbeing: A randomized controlled trial. Anthrozoös, 30(3), 397-414.

[4] Bücker, S., Nuraydin, S., Simonsmeier, B. A., Schneider, M., \& Luhmann, M. (2018). Subjective well-being and academic achievement: A meta-analysis. Journal of Research in Personality, 74, 83-94.

[5] Claessens, B. J., Van Eerde, W., Rutte, C. G., \& Roe, R. A. (2007). A review of the time management literature. Personnel review.

[6] Denovan, A., \& Macaskill, A. (2017). Stress and subjective well-being among first year UK undergraduate students. Journal of Happiness Studies, 18(2), 505-525.

[7] Denovan, A., \& Macaskill, A. (2017). Stress and subjective well-being among first year UK undergraduate students. Journal of Happiness Studies, 18(2), 505-525.

[8] Diener, E. (2009). Subjective well-being. In The science of well-being (pp. 11-58). Springer, Dordrecht.

[9] Diener, E., Diener, M., \& Diener, C. (2009). Factors predicting the subjective well-being of nations. In Culture and well-being (pp. 43-70). Springer, Dordrecht.

[10] FAN, C. Y., SUN, X. J., \& LIU, H. S. (2012). Time management disposition and subjective well-being in undergraduate students [J]. Psychological Development and Education, 1, 99-104.

[11] Hayes, A. F. (2009). Beyond Baron and Kenny: Statistical mediation analysis in the new millennium. Communication monographs, 76(4), 408-420. 
[12] Judge, T. A., \& Bono, J. E. (2001). Relationship of core self-evaluations traits-self-esteem, generalized self-efficacy, locus of control, and emotional stability-with job satisfaction and job performance: A meta-analysis. Journal of applied Psychology, 86(1), 80.

[13] Kim, B., \& Kim, Y. (2017). College students' social media use and communication network heterogeneity: Implications for social capital and subjective well-being. Computers in Human Behavior, 73, 620-628.

[14] Macan, T. H., Shahani, C., Dipboye, R. L., \& Phillips, A. P. (1990). College students' time management: Correlations with academic performance and stress. Journal of educational psychology, 82(4), 760.

[15] Misra, R., \& McKean, M. (2000). College students' academic stress and its relation to their anxiety, time management, and leisure satisfaction. American journal of Health studies, 16(1), 41.

[16] Osmond, T. W. (1994). Stress and time management: The development of an awareness and training program for older children (Doctoral dissertation, Memorial University of Newfoundland).

[17] Romppel, M., Herrmann-Lingen, C., Wachter, R., Edelmann, F., Düngen, H. D., Pieske, B., \& Grande, G. (2013). A short form of the General Self-Efficacy Scale (GSE-6): Development, psychometric properties and validity in an intercultural non-clinical sample and a sample of patients at risk for heart failure. GMS Psycho-Social-Medicine, 10.

[18] Roth, R. A., Suldo, S. M., \& Ferron, J. M. (2017). Improving middle school students' subjective well-being: Efficacy of a multicomponent positive psychology intervention targeting small groups of youth. School Psychology Review, 46(1), 21-41.

[19] Samdal, O. (2001). The school environment as a risk or resource for students' health-related behaviours and subjective well-being.

[20] Schnettler, B., Miranda, H., Lobos, G., Orellana, L., Sepúlveda, J., Denegri, M., \& Grunert, K. G. (2015). Eating habits and subjective well-being. A typology of students in Chilean state universities. Appetite, 89, 203-214.

[21] Suldo, S. M., Hearon, B. V., Bander, B., McCullough, M., Garofano, J., Roth, R. A., \& Tan, S. Y. (2015). Increasing elementary school students' subjective well-being through a classwide positive psychology intervention: Results of a pilot study. Contemporary School Psychology, 19(4), 300-311.

[22] Terry, K. P. S. (2002). The effects of online time management practices on self-regulated learning and academic self-efficacy (Doctoral dissertation, University Libraries, Virginia Polytechnic Institute and State University.

[23] Zhang, Y., \& Chen, M. (2018). Character strengths, strengths use, future self-continuity and subjective well-being among Chinese university students. Frontiers in psychology, 9, 1040. 